\title{
Cognitive and behavioral status of low birth weight preterm children raised in a developing country at preschool age
}

\author{
Júlia L. do Espírito Santo, ${ }^{1}$ Mirna W. Portuguez, ${ }^{2}$ Magda L. Nunes ${ }^{2}$
}

\begin{abstract}
Objective: To assess cognitive and behavioral development at preschool age of children born preterm and with low birth weight and raised in a developing country.

Methods: Prospective cross-sectional study of 80 neonates born in a university hospital in southern Brazil. Neuropsychological assessment at age 4-5 years included the Wechsler Preschool and Primary Scale of Intelligence (WPPSI), Conners' Parent Rating Scale-Revised, Denver test and neurological examination. Perinatal and early neuropsychomotor development information was collected from the database during follow-up. Results were related to birth weight, sex and gestational age.

Results: WPPSI scores were: total intelligence quotient (IQ) 88.00 \pm 16.96 , verbal IQ $89.72 \pm 16.72$, and executive IQ $88.12 \pm 15.71$ for the group with less than 1,500 grams; and total IQ 91.11 \pm 14.73 , verbal IQ 93.36 \pm 12.65 , and executive IQ $90.20 \pm 16.06$ for the group between 1,500 and 2,500 grams. The best scores were obtained in tests that evaluated capacity of abstraction and symbolization, picture completion and common perception, in which only $5 \%$ and $6.3 \%$ of the children had abnormal results, respectively. The lowest scores were obtained in tests that evaluated visual-motor coordination and flexibility-speed of reasoning, in which $27.5 \%$ and $16.3 \%$ of the children had abnormal results, respectively. A total of $32.5 \%$ had abnormal results in the arithmetic tests. Behaviors related to attention deficit/ hyperactivity disorder (ADHD) were observed in $48 \%$ of the sample. Low score in the Bayley Mental Scale and abnormal result in the Denver test were significantly correlated to ADHD ( $p=0.017$ and $p=0.004)$. Abnormal results in the Bayley Mental Scale $(p<0.001)$, Denver test $(p<0.001)$ and neurological examination $(p=0.002)$ were associated with lower IQ.
\end{abstract}

Conclusions: The results revealed an increased incidence of behavioral and cognitive disorders at preschool age.

J Pediatr (Rio J). 2009;85(1):35-41: ADHD, low birth weight, prematurity, cognition, behavior.

\section{Introduction}

Most of the studies published in the literature concerning follow-up of preterm newborns focus mainly on aspects of motor development. Furthermore, services generally provide follow-up for 2 years, as at this age most of the neurological and sensory abnormalities could be easily identified. ${ }^{1}$ However, after the nineties, with the advances that resulted in a longer survival of preterm newborns, the early recognition of cognitive and behavioral deficits in this population with higher risks of adversities in the long term follow-up became significant in terms of quality of future life. ${ }^{2,3}$
As intellectual, social and emotional skills are required to an effective functioning in school, deficits in development become particularly evident when children reach preschool age. ${ }^{4}$ Studies indicate that low birth weight preterm children show a significantly poorer school performance when compared to children of the same age. ${ }^{4-9}$

Premature birth may affect school performance through cognitive and behavioral problems, especially by perceptive disorders of attention and hyperactivity. ${ }^{10}$ Data regarding the neuropsychological status of preterm newborns are available

1. Fellow Neuropsychology, Divison of Neurology, Hospital São Lucas, Pontifícia Universidade Católica do Rio Grande do Sul (PUCRS), Porto Alegre, RS, Brazil. 2. PhD. Associate professor, School of Medicine, PUCRS, Porto Alegre, RS, Brazil.

No conflicts of interest declared concerning the publication of this article.

Suggested citation: do Espírito Santo JL, Portuguez MW, Nunes ML. Cognitive and behavioral status of low birth weight preterm children raised in a developing country at preschool age. J Pediatr (Rio J). 2009;85(1):35-41.

Manuscript received Mar 31 2008, accepted for publication Oct 272008.

doi:10.2223/JPED.1859 
in the literature but the majority of these studies were conducted in developed countries. ${ }^{4,5,7,9-12}$ Few studies of follow-up regarding school or preschool performance of very low birth weight preterm infants were published involving South American populations, ${ }^{8}$ where specialized health care resources for following this particular population are generally not available.

The main objective of this study was to assess cognitive and behavioral development at preschool age of low birth weight preterm children born and raised in a developing country.

\section{Methods}

This is a cross-sectional study of infants born preterm (less than 37 gestational weeks) and with low birth weight (less than 2,500 grams), selected from a birth cohort from the Neonatal Intensive Care Unit of Hospital São Lucas at Pontifícia Universidade Católica do Rio Grande do Sul (PUCRS). All patients were admitted through the Brazilian National Health System (Sistema Único de Saúde, SUS) and were classified as persons with low socioeconomic status.

During the year 1999, 222 low birth weight preterm infants were admitted; out of these, 25 died before discharge. Respectively, 60 to $70 \%$ of these patients were regularly being followed at the neurodevelopment outpatient clinic of the same institution between 1999 and $2000 .{ }^{13}$ Children who had previous neurological disorders at the neonatal period ( $\mathrm{n}=$ 22), visual or hearing deficit, comprehensive language disorders or severe mental deficiency that made them unable to perform tasks required from the neuropsychological assessment were excluded. After an active search for mailing addresses, patients were invited to participate in the study; letters were sent even to the ones that were not regularly being followed.

All patients aged between 4 years and 5 years and 11 months were submitted to neuropsychological evaluation (Wechsler Preschool and Primary Scale of Intelligence, WPPSI, ${ }^{14}$ and Conners' Parent Rating Scale-Revised, CPRS- ${ }^{15}$ ), in addition to complete clinical neurological examination ${ }^{16}$ and Denver test. ${ }^{17}$ The neuropsychological evaluation was performed by the same examiner (J.L.E.S.) during a special visit and results were discussed with an expert (M.W.P.). The neurological evaluation and Denver test were performed by the Neurology fellow of the clinic during the routine visit. The child's clinical and perinatal history was reviewed in the database, as well as the results of the Bayley Infant Development Scale ${ }^{18}$ previously applied between 12 and 24 months.

The WPPSI is used to assess intelligence in preschoolers and young children and contains 12 subtests, six in the Performance Scale and six in the Verbal Scale. A raw score is first obtained on each subtest and then converted to a scaled score within the examinee's own age group using a table in the
WPPSI manual. A score below 70 suggests a deficit (mental retardation), 70-79 means boundary, 80-89 means a low average intelligence quotient (IQ), 90-109 average, 110-119 average - superior and 120-129 superior.

The CPRS-R is widely used in different populations to evaluate behavior and for the assessment of attention deficit/ hyperactive disorder (ADHD). It has already been adapted and validated to Portuguese. ${ }^{19}$ The test can be applied to parents or caregivers. It contains subscales for the assessment of conduct problems, cognitive problems, family problems, emotional problems and anxiety problems. It includes information regarding oppositional behavior, inattention, hyperactivity, perfectionism, social problems and psychosomatic problems. The scoring varies from 38 to 90 ; scores above 64 are suggestive of behavioral problems.

Data obtained from the WPPSI and CPRS-R were correlated to results from the Denver test, clinical neurological examination and previous score in the Bayley Mental Scale and Denver test. Statistical analysis included Student $t$ test and chi-square.

Sample calculation was based on the information provided by editors of the scales used and supposes a standard deviation of 5 points in CPRS-R (with a maximum error probability of 1.2 unit for the average) and a standard deviation of 15 units in the WPPSI (with a maximum error probability of 3.5 points in the average estimate). A sample size of 70 patients was calculated with a confidence interval of $95 \%$.

The study was approved by the Research Ethics Committee of PUCRS and patients were included after the signature of informed consent.

\section{Results}

From the 1999 birth cohort, 175 patients were eligible for the study and 31 were unavailable after a search for mailing address and telephone. Based on the previous sample calculation, the first 40 males and 40 females who scheduled appointments, whether regularly followed or not, were included in the study. Among the patients included, 50 were being followed since discharge and 30 had not been regularly followed during the first years of life.

Regarding the perinatal data, out of the 80 infants evaluated, 48 were born through a cesarean section, 77 (96.3\%) presented some type of neonatal problem, being respiratory dysfunction the most frequent $(73.8 \%)$ and the one mostly found in the male sex $(p=0.022)$, followed by jaundice $(61.3 \%)$, and sepsis $(12.5 \%)$. Birth weight varied from 675 to 2,475 grams (mean $1,787.88 \pm 502.94$ ). Regarding birth weight, $69 \%$ of the infants had birth weight below 2,500 and over 1,500 grams, $31 \%$ had birth weight below 1,500 grams (among them only 7 patients had birth weight below 1,000 grams). Gestational age (GA) varied from 24 to 36 weeks (mean 32.34 2.99), 61\% had GA between 34-36 weeks, $33 \%$ between $31-33$ weeks, and $6 \%$ below 30 weeks. 
Table 1 - Results from WPPSI subtests

\begin{tabular}{|c|c|c|c|c|}
\hline Subtests & Mean \pm SD & $\begin{array}{l}\text { Minimum } \\
\text { score }\end{array}$ & $\begin{array}{l}\text { Maximum } \\
\text { score }\end{array}$ & $\begin{array}{l}\% \text { of children with } \\
\text { abnormal results }\end{array}$ \\
\hline Information & $8.99 \pm 3.05$ & 1 & 15 & 10.0 \\
\hline Vocabulary & $8.29 \pm 2.23$ & 2 & 15 & 7.5 \\
\hline Arithmetic & $8.06 \pm 4.02$ & 1 & 18 & 32.5 \\
\hline Similarities & $10.46 \pm 2.56$ & 2 & 15 & 5.0 \\
\hline Comprehension & $7.96 \pm 2.69$ & 1 & 18 & 17.5 \\
\hline Animal pegs & $7.78 \pm 3.14$ & 1 & 17 & 27.5 \\
\hline Picture completion & $10.33 \pm 2.96$ & 3 & 18 & 6.3 \\
\hline Mazes & $7.90 \pm 2.65$ & 2 & 16 & 16.3 \\
\hline Geometric design & $8.04 \pm 3.02$ & 1 & 19 & 16.3 \\
\hline Block design & $8.20 \pm 2.59$ & 1 & 14 & 13.8 \\
\hline
\end{tabular}

SD = standard deviation; WPPSI = Wechsler Preschool and Primary Scale of Intelligence.

In the WPPSI, the best scores were obtained in the tests that evaluate capacity of abstraction and symbolization $(10.46 \pm 2.56)$ and picture completion (10.33 \pm 2.96$)$, which evaluates common perception. In these tests, only $5 \%$ and $6.3 \%$ of the children had abnormal results, respectively. The lowest scores were obtained in tests that evaluate visual-motor coordination $(7.90 \pm 2.65)$ and flexibility and speed of reasoning (7.78 \pm 3.14$)$, in which, $27.5 \%$ and $16.3 \%$ of the children evaluated had abnormal results, respectively. The highest frequency of abnormal results was observed in the arithmetic tests (32.5\%) (Table 1 ).

Comparing WPPSI scores and birth weight, the very low birth weight ( $<1,500$ grams) group had lower IQ scores (total IQ 88.00 16.96 , verbal IQ 89.72 \pm 16.72 , and executive IQ $88.12 \pm 15.71$ ), which could be classified as average/low level. Children with birth weight $<2,500$ grams and $>1,500$ grams had an average IQ level (total IQ $91.11 \pm 14.73$, verbal IQ

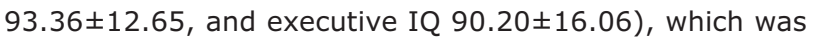
superior to that of the first group. However, differences were not statistically significant $(p=0.407, p=0.285, p=0.590$, respectively).

Comparing total IQ to the score previously obtained in the Bayley Mental Scale, Denver test and neurological examination, a significant association was observed between these variables and lower IQ (Table 2).

The indexes obtained in the CPRS-R are shown in Table 3.

From the sample, 48 patients (60\%) had scores over 64 in this scale, suggesting the existence of a behavioral or emotional problem. Behavior related to the Diagnostic and Statistical Manual of Mental Disorders, 4th edition (DSM-IV), "hyperactive-impulsive" criteria followed by "cognitive problems/inattention," and "hyperactivity" were the most frequently observed and present among 43.3 to $48 \%$ of the children. Comparing results from the CPRS-R to gestational age, it was verified that higher scores in the "perfectionism" and "emotional liability" indexes were significant when associated with the group with less than 33 weeks $(p=0.004, p=$ 0.032 ). However, no statistically significant difference was observed between groups when stratified by birth weight. Significant differences were observed related to gender in two indexes of CPRS-R, the psychosomatic was more altered in boys $(p=0.041)$ and the ADHD was more prevalent in girls ( $p$ $=0.041$ ). Results from the CPRS-R were not significantly different among children that had already started school ( $\mathrm{n}=$ $43)$ when compared to the ones that had not $(n=37)$.

Comparing results from the CPRS-R at $1-2$ years of age to Denver test at 4-5 years of age there was a significant association between the abnormal Denver at 4-5 years age and the following CPRS-R indexes: oppositional behavior ( $p=$ $0.032)$, ADHD ( $p=0.014)$, DSM-IV inattentive $(p=0.050)$, and DSM-IV inattentive/impulsive-hyperactive $(p=0.004)$.

Comparing the behavioral questions of the CPRS-R with the Bayley mental test previously applied to the patients (between 12 and 24 months of age) it was possible to verify a significant association between the DSM-IV inattentive/ impulsive-hyperactive index and lower scores in the Bayley mental test $(p=0.017)$.

Neurological examination performed at 4-5 years of age was considered abnormal in 10 patients ( 2 girls and 8 boys) 
38

Table 2 - Comparison between WPPSI total IQ and Mental and Motor Bayley Development Scales (previously done), neurological examination, Denver Test, and neonatal problems

\begin{tabular}{|c|c|c|c|}
\hline \multirow[b]{2}{*}{ Items } & \multicolumn{2}{|c|}{ Total IQ } & \multirow[b]{2}{*}{$\mathbf{p}$} \\
\hline & Inferior, n (\%) & Average/Superior, n (\%) & \\
\hline Bayley mental & & & $<0.001 *$ \\
\hline Normal & $4(15.4)$ & $22(84.6)$ & \\
\hline Questionable & $3(16.7)$ & $15(83.3)$ & \\
\hline Below & $6(100.0)$ & $0(00.0)$ & \\
\hline Bayley motor & & & $0.015^{*}$ \\
\hline Normal & $6(16.2)$ & $31(83.8)$ & \\
\hline Questionable & $4(44.4)$ & $5(55.6)$ & \\
\hline Below & $3(75.0)$ & $1(25.0)$ & \\
\hline Neurological exam & & & $0.007^{+}$ \\
\hline Normal & $12(17.1)$ & $58(82.9)$ & \\
\hline Abnormal & $6(60.0)$ & $4(40.0)$ & \\
\hline Denver test & & & $<0.001^{*}$ \\
\hline Normal & $8(13.3)$ & $52(86.7)$ & \\
\hline Questionable & $3(30.0)$ & $7(70.0)$ & \\
\hline Abnormal & $7(70.0)$ & $3(30.0)$ & \\
\hline Neonatal disorders & & & $1.000^{+}$ \\
\hline Yes & $18(23.4)$ & $59(76.6)$ & \\
\hline No & $0(0.0)$ & $3(100.0)$ & \\
\hline
\end{tabular}

WPPSI $=$ Wechsler Preschool and Primary Scale of Intelligence.

* Chi-square.

${ }^{\dagger}$ Fischer's test.

Table 3 - Scores obtained in the Conners' Parent Rating Scale-Revised and percentage of children with abnormal results for each variable

\begin{tabular}{lccc}
\hline Variable & Mean \pm SD & Variation of scores & \% of abnormal results \\
\hline Oppositional behavior & $62.43 \pm 12.63$ & $39-90$ & 36.3 \\
Cognitive deficits /inattention & $65.39 \pm 14.04$ & $44-90$ & 43.8 \\
Hyperactivity & $64.08 \pm 12.68$ & $41-90$ & 43.8 \\
Anxious-shy & $58.08 \pm 12.28$ & $38-90$ & 27.5 \\
Perfectionism & $59.19 \pm 9.58$ & $41-85$ & 25 \\
Social problems & $61.71 \pm 14.85$ & $44-90$ & 31.3 \\
Psychosomatic & $62.14 \pm 14.89$ & $42-90$ & 41.3 \\
ADHD index & $61.93 \pm 13.36$ & $40-90$ & 33.8 \\
Restless-impulsive & $62.38 \pm 12.84$ & $39-90$ & 35.0 \\
Emotional ability & $55.74 \pm 11.92$ & $39-83$ & 21.3 \\
Conners' global index & $60.89 \pm 11.63$ & $38-90$ & 31.3 \\
DSM-IV inattention & $61.99 \pm 13.63$ & $41-90$ & 36.3 \\
DSM-IV hyperactive-impulsive & $66.28 \pm 12.71$ & $43-90$ & 48.8 \\
DSM-IV ADHD total & $65.44 \pm 12.84$ & $41-90$ & 41.3 \\
\hline
\end{tabular}

$\mathrm{ADHD}=$ attention deficit/hyperactive disorder; DSM-IV = Diagnostic and Statistical Manual of Mental Disorders, 4th edition; SD = standard deviation. 
$(p=0.043)$. An association between children with psychosomatic behavior and altered neurological exam was also observed $(p=0.033)$.

\section{Discussion}

Low birth weight preterm babies are diagnosed as a group in disadvantage concerning school success involving intelligence and behavioral problems when compared to term infants. Deficits were shown in the cognitive and academic functioning, such as verbal and non-verbal intelligence, language skills, arithmetical reasoning, and reading. Types of behavioral problems mostly associated to low birth weight and prematurity vary from hyperactivity and attention disorder to problematic social behavior and depression. ${ }^{1,5,6,20-25}$ Besides, extremely low birth weight infants have higher risk for neurological abnormalities, developmental delay, and functional delay. ${ }^{12,21,22}$

In this study we observed that $60 \%$ of the low birth weight preterm infants from our cohort obtained high scores in the Conners' scale, suggesting the existence of a behavioral or emotional problem, among them $48 \%$ had behavioral alterations suggestive of ADHD at age 4-5 years. Intellectual level was predominantly classified in average and low-average. Alterations of Bayley Mental Scale previously applied were related to outcome with both cognitive and behavioral problems. Criteria for attention deficit were prevalent in the female sex; however, neurological problems were more prevalent in the male sex.

Limitations of this study could be related to loss of children during the years of follow-up and the absence of a control group. However, as invitation letters were sent to the entire cohort, strict exclusion criteria were used and the study included patients who were not being regularly followed, the possible selection bias of analyzing just the ones that were more handicapped was as much as possible avoided.

In a meta-analysis that reviewed 227 studies regarding behavioral and cognitive outcome of preterm infants with birth weight inferior to 2,500 grams it was observed that children who were born preterm are at risk for lower cognitive scores and their immaturity at birth is directly proportional to the mean cognitive scores at school age, and an increased incidence of ADHD was also observed. ${ }^{7}$ In a cross-cultural study involving preterm newborns from four different countries, similar higher scores for ADHD were observed and biological mechanisms related to prematurity were suggested to contribute to this outcome. ${ }^{3,26}$

The Conners' scale is widely used in children and adolescents from different countries and cultures to evaluate behavior and predictors of ADHD. In the last 5 years, 250 articles cited in MEDLINE used this scale and, among them, three were used in previous preterm newborns. In those studies preterm newborns with birth weight below 2,500, 1,500 and 1,000 grams were included. In all of them, and similar to our findings, an increased risk for ADHD behaviors was observed, and in the last one this risk was associated with motor disabilities previously observed at 2 years of age.

Previous studies have also showed that prematurity influences cognitive outcome and that the cognitive deficits tend to be lately observed, especially those affecting cognitive functions. Several authors agree when they state that low birth weight preterm children have a worse performance in intelligence tests. $8,9,21,27-29$

Méio et al. ${ }^{8}$ have analyzed, in southeastern Brazil, a group of preterm children with birth weight below 1,500 grams who have obtained slightly lower IQ scores than those observed in our sample. Perhaps the slightly better results from our cohort were due to the fact that nearly $70 \%$ had birth weight between 1,500 and 2,500 grams.

Our results showed a relation between lower gestational age and emotional problems. This increased incidence of behavioral problems in preterm babies was previously reported by several authors, ${ }^{4,20,29,30}$ and these problems could reflect even in adolescence. ${ }^{31}$

Low birth weight preterm infants have deficits in the cognitive and motor performance, and these aspects impact on their education and quality of life. ${ }^{4}$ As it has been reported before, in a population of southern Brazil, prematurity and low birth weight were considerable risk factors for developmental delay. ${ }^{32}$

In a previous study, of this same cohort, we have observed a higher risk of language acquisition delay. Furthermore, the ones with language delay had also lower cognitive and behavior scores than the ones with normal language acquisition. ${ }^{33}$ It is clear that preterm children at school age continue to show significant deficits in several areas, correlating with motor and cognitive performances. ${ }^{10}$

Our findings suggest that low birth weight preterm newborns, even in a birth range predominantly between 1,500 and 2,500 grams, have a considerable high prevalence of cognitive and behavioral disorders (including predictors of ADHD) at preschool age, when compared to controls described in the literature. Our results also agree with data from other cohorts studied at similar ages, such as the EPICure study, in which the results obtained revealed $41 \%$ of cognitive impairment at 6 years of age. ${ }^{30}$ However, in this specific study, these results were easily understood as the sample focused on preterm newborns with less than 26 weeks of GA.

We have also shown that suspicion for this outcome could be early detected during follow-up using the Bayley Mental Scale between 12-24 months. This finding agrees with the United Kingdom study, in which the authors also found lower scores of Bayley mental children who had been preterm and born with low birth weight. ${ }^{34}$ 
The main contribution of this study was to show an increased risk of behavioral problems, even in late preterm newborns, which can be early suspected during follow-up. Additionally, the introduction of a scale that has a good sensitivity for ADHD and behavioral problems in a population with high risk for this dysfunction seems to be helpful.

Considering that higher rates of survival for low birth weight preterm babies were being achieved, even in developing countries, the results of this study, which should be confirmed by further studies in larger populations including controls, may contribute to improve planning of health management and educational needs for this high risk population in a developing country.

\section{References}

1. Marlow N. Neurocognitive outcome after very preterm birth. Arch Dis Child Fetal Neonatal Ed. 2004;89:F224-8.

2. Anderson PJ, Doyle LW. Cognitive and educational deficits in children born extremely preterm. Semin Perinatol. 2008; 32: 51-8.

3. Hille ET, den Ouden AL, Saigal S, Wolke D, Lambert M, Whitaker $A$, et al. Behavioural problems in children who weigh $1000 \mathrm{~g}$ or less at birth in four countries. Lancet. 2001;357: 1641-3.

4. Fazzi E, Orcesi S, Telesca C, Ometto A, Rondini G, Lanzi G. Neurodevelopmental outcome in very low birth weight infants at 24 months and 5 to 7 years of age: changing diagnosis. Pediatr Neurol. 1997; 17:240-8.

5. Anderson P, Doyle LW; Victorian Infant Collaborative Study Group. Neurobehavioral outcomes of school-age children born extremely low birth weight or very preterm in the 1990s. JAMA. 2003;289:3264-72.

6. Weindrich $D$, Jennen-Steinmetz $C$, Laucht M, Schmidt MH. Late sequelae of low birthweight: mediators of poor school performance at 11 years. Dev Med Child Neurol. 2003;45: 463-9.

7. Bhutta AT, Cleves MA, Casey PH, Cradock MM, Anand KJ. Cognitive and behavioral outcomes of school-aged children who were born preterm: a meta-analysis. JAMA. 2002;288:728-37.

8. Méio MD, Lopes CS, Morsch DS, Monteiro AP, Rocha SB, Borges $\mathrm{RA}$, et al. Desenvolvimento cognitivo de crianças prematuras de muito baixo peso na idade pré-escolar. J Pediatr (Rio J). 2004; 80:495-502.

9. Breslau N, Johnson EO, Lucia VC. Academic achievement of low birthweight children at age 11: the role of cognitive abilities at school entry. J Abnorm Child Psychol. 2001;29:273-9.

10. Cooke RW, Foulder-Hughes L. Growth impairment in the very preterm and cognitive and motor performance at 7 years. Arch Dis Child. 2003;88:482-7.

11. Castro L, Yolton K, Haberman B, Roberto N, Hansen NI, Ambalavanan, et al. Bias in reported neurodevelopmental outcomes among extremely low birth weight survivors. Pediatrics. 2004;114:404-10.
12. Vohr BR, Wright LL, Dusick AM, Mele L, Verter J, Steichen JJ, et al. Neurodevelopmental and functional outcomes of extremely low birth weight infants in the National Institute of Child Health and Human Development Neonatal Research Network, 1993-1994. Pediatrics. 2000;105:1216-26.

13. Fossari MA. Seguimento de recém nascidos pré-termo da UTI Neonatal do Hospital São Lucas da PUCRS [dissertação]. Porto Alegre: Pontifícia Universidade Católica do Rio Grande do Sul; 2003.

14. Wechsler D. Wechsler Preschool and Primary Scale of Intelligence. San Antonio, TX: The Psychological Corporation; 1989.

15. Conners CK. Conners' rating scales-revised. North Tonawanda, NY: Multi-Health Systems; 2001.

16. El Ammar GL, Paim LL, Soder R, Nunes ML. Modelo de anamnese e exame neurológico (anexo I). In: Nunes ML, Marrone CA, organizadores. Semiologia neurológica. Porto Alegre: EDIPUCRS; 2002. p. 587-96.

17. Frankenburg WK, Dodds JB, editors. Denver II. Denver, CO: Denver Developmental Materials; 1996.

18. Bayley N. Bayley Scales of Infant Development. 2nd ed. San Antonio, TX: Psychological Corporation; 1993.

19. Barbosa GA, Dias MR, Gaião AA. Validácion factorial de los índices de hiperactividad del cuestionário de Conners en escolares de João Pessoa - Brasil. Infanto Rev Neuropsiquiatr Infanc Adolesc. 1997;5:118-25.

20. Vanhaesebrouck P, Allegaert K, Bottu J, Debauche C, Devlieger $H$, Docx M; Extremely Preterm Infants in Belgium Study Group. The EPIBEL study: outcomes to discharge from hospital for extremely preterm infants in Belgium. Pediatrics. 2004;114: 663-75.

21. Fearon $P, O^{\prime}$ Connell $P$, Frangou $S$, Aquino $P$, Nosarti $C$, Allin $M$, et al. Brain volumes in adult survivors of very low birth weight: a sibling-controlled study. Pediatrics. 2004;114:367-71.

22. Kesler SR, Ment LR, Vohr B, Pajot SK, Schneider KC, Katz KH, et al. Volumetric analysis of regional cerebral development in preterm children. Pediatr Neurol. 2004;31:318-25.

23. Sasaluxnanon C, Kaewpornsawan T. Risk factor of birth weight below 2,500 grams and attention deficit hyperactivity disorder in Thai children. J Med Assoc Thai. 2005;88:1514-8.

24. Kulseng $S$, Jennekens-Schinkel $A$, Naess $P$, Romundstad $P$, Indredavik $M, V i k T$, et al. Very-low-birthweight and term small-for-gestational-age adolescents: attention revisited. Acta Paediatr. 2006;95:224-30.

25. Jeyaseelan D, O'Callaghan M, Neulinger K, Shum D, Burns Y. The association between early minor motor difficulties in extreme low birth weight infants and school age attentional difficulties. Early Hum Dev. 2006;82:249-55.

26. Nosarti C, Allin MP, Frangou S, Rifkin L, Murray RM. Hyperactivity in adolescents born very preterm is associated with decreased caudate volume. Biol Psychiatry. 2005;57:661-6.

27. Fattal-Valevski A, Leitner Y, Kutai M, Tal-Posener E, Tomer A, Lieberman $D$, et al. Neurodevelopmental outcome in children with intrauterine growth retardation: a 3-year follow up. J Child Neurol. 1999;14:724-7.

28. Richards M, Hardy R, Kuh D, Wadsworth ME. Birth weight and cognitive function in the British 1946 birth cohort: longitudinal population based study. BMJ. 2001;322:199-203.

29. Strauss RS. Adult functional outcome of those born small for gestational age: twenty-six-year follow-up of the 1970 British Birth Cohort. JAMA. 2000;283:625-32. 
30. Marlow N, Wolke D, Bracewell MA, Samara M; EPICure Study Group. Neurologic and developmental disability at six years of age after extremely preterm birth. N Engl J Med. 2005;352: 9-19.

31. Saigal S, Pinelli J, Hoult L, Kim MM, Boyle M. Psychopathology and social competencies of adolescents who were extremely low birth weight. Pediatrics. 2003;111:969-75.

32. Halpern R, Giugliani ER, Victora CG, Barros FC, Horta BL. Fatores de risco para suspeita de atraso no desenvolvimento neuropsicomotor aos 12 meses de vida. J Pediatr (Rio J). 2000; 76:421-8.

33. Schirmer CR, Portuguez MW, Nunes ML. Clinical assessment of language development in children at age 3 years that were born preterm. Arq Neuropsiquiatr. 2006;64:926-31.
34. Wood NS, Marlow N, Costeloe K, Gibson AT, Wilkinson AR. Neurologic and developmental disability after extremely preterm birth. EPICure Study Group. N Engl J Med. 2000;343:378-84.

Correspondence:

Magda Lahorgue Nunes

Serviço de Neurologia do Hospital São Lucas - PUCRS

Av. Ipiranga, 6690/220

CEP 90610-000 - Porto Alegre, RS - Brazil

E-mail: nunes@pucrs.br 